\title{
Giving a temporal context to drought and frost vulnerability of trees
}

\author{
Rosana López based on reviews by Sean Gleason and Jordi Martínez \\ Vilalta
}

\section{A recommendation of:}

Guillaume Charrier, Nicolas Martin-Stpaul, Claire Damesin, Nicolas Delpierre, Heikki Hänninen, José Torres-Ruiz, Hendrik Davi. Interaction of drought and frost in tree ecophysiology: rethinking the timing of risks (2020), hal, 02475505, ver. 4 peer-reviewed and recommended by Peer Community in Forest and Wood Sciences. https://hal.archivesouvertes.fr/hal-02475505v4

\section{Open Access}

Submitted: 28 April 2020, Recommended: 29 September 2020

Cite this recommendation as:

Rosana López (2020) Giving a temporal context to drought and frost vulnerability of trees. Peer Community in Forest and Wood Sciences, 100001. 10.24072/pci.forestwoodsci.100001

Published: 14 Oct 2020

Copyright: This work is licensed under the Creative Commons Attribution-NoDerivatives 4.0 International License. To view a copy of this license, visit http://creativecommons.org/licen ses/by-nd/4.0/
Range limits of forest species are frequently imposed by spatial gradients in climatic variables. Tolerance to maximum and minimum temperatures, including short-term extremes, and tolerance to desiccation are crucial limiting factors for plant survival and often appear interrelated (Box 1995; Choat et al. 2018). Increasing temperatures, more frequent and extreme droughts and late frost events associated with global climate change will affect the dynamics of forest ecosystems and have the potential to dramatically increase plant mortality and accelerate species range shifts if plants are not able to adapt in situ to the novel climate regimes (Parmesan 2006; Choat et al., 2012). This is particularly important at species range edges, where climatic conditions may not be sufficient to impose mortality on individuals directly, but trees experience greater physiological stress, which influences such factors as dispersal, habitat selection, and subsequent reproductive fitness (Parmesan 2006). In such marginal situations, where gene flow may be also restricted (López de Heredia et al. 2010), the effectiveness of adjustment through natural selection is limited resulting in increased vulnerability to extreme climatic events and to a higher risk of mortality of trees.

Tree responses to drought and frost have been extensively studied at many scales from ecophysiology to molecular biology across a large range of species inhabiting diverse biomes (Sakai and Larcher 1987; Bréda et al. 2006). Avoiding dehydration of tissues to maintain cellular viability and function is at the basis of the plant strategy to deal with both constraints as shown by Charrier et al. (2020). These authors go one step further and discuss the impact of the interaction of drought and frost on tree water status and carbon metabolism with special emphasis on the temporal context. Plants from temperate and boreal regions show changes in their resistance to freezing temperature throughout the year (Bower and Aitken 2006) and xylem becomes more resistant to cavitation with cambial age (Rodríguez-Zaccaro et al. 2019). Including timing in this 
framework involves incorporating phenology. This will be a fundamental step to model species distribution limits in the face of climate change since most observations of climate-change responses have involved alterations of species' phenologies (Parmesan et al. 2006). For example, the onset of the growing season of trees in temperate Europe is 2.3 days ahead per decade during the last 40 years (Parmesan et al. 2006). Moreover, some studies have shown that climatic constraints limit species distribution mainly because of their impact in phenology rather than their impact on drought and frost mortality (Morin et al. 2007). However, longer growing seasons along with more frequent extreme events increase the probability of longlived organisms such as trees to experience frosts and drought during the same growing season or one of them after uncompleted recovery of the other in some latitudes. Over the last decade much attention has been devoted to the recovery of growth and ecological function after stressful events (Lloret et al. 2011). Some dendroecological studies have shown for example that resilience to extreme droughts might be constrained by having experienced more frequent droughts, thus exceeding the potential for acclimation of the tree (Bose et al. 2020). Drought can result in chronic hydraulic impairment which can last moths to years (Anderegg et al. 2015) and for some species also in cavitation fatigue, i.e. a progressive increase in vulnerability to cavitation (Hacke et al. 2001), thus increasing vulnerability to subsequent drought and frost events.

Models have proved to be useful tools for synthetizing and integrating climate and soil properties with key functional traits in order to determine desiccation dynamics, carbon metabolism and plant survival during drought of frost (Martin-StPaul et al., 2017; Charrier et al. 2018; Blackman et al., 2019). However, models are currently limited by gaps in our understanding of the fundamental physiological mechanisms that constrain species ranges. Most common approaches to studying species range shifts are related to climatic niches and overlook the processes and traits involved in drought or frost tolerance (Cheaib et al. 2012). Process-based models based on plant hydraulics seem promising providing the link between environmental cues and plant responses, although disregarding carbon metabolism will not give us predictive understanding of system changes such as those due to climate fluctuations (Mackay et al. 2015). New modeling approaches need to be developed not only for better drought prediction performance but for the interaction of drought with other factors. Charrier et al. (2020) offer a framework for improving process-based models with the aim to provide better prediction of carbon and water economy, organ development and ultimately species distribution limits in the face of warmer winters and more frequent winter droughts at high altitudes and late frosts events.

\section{References}

Anderegg WR, Schwalm C, Biondi F, Camarero JJ, Koch G, Litvak M, Ogle K, Shaw JD, Shevliakova E, Williams A (2015) Pervasive drought legacies in forest ecosystems and their implications for carbon cycle models.

Science 349: 528-532. doi: https://doi.org/10.1126/science.aab1833

Blackman CJ, Li X, Choat B, Rymer PD, De Kauwe MG, Duursma RA, Tissue DT, Medlyn BE (2019) Desiccation time during drought is highly predictable across species of Eucalyptus from contrasting climates. New Phytologist 224: 632-643. doi: https://doi.org/10.1111/nph.16042

Box EO (1995) Factors determining distributions of tree species and plant functional types. Vegetatio 121, 101-116 (1995). doi: https://doi.org/10.1007/BF00044676

Bower AD, Aitken SN (2006) Geographic and seasonal variation in cold hardiness of whitebark pine. Can J For Res 36:1842-1850. doi: https://doi.org/10.1139/x06-067

Bréda N, Huc R, Granier A, Dreyer E (2006) Temperate forest trees and stands under severe drought: a review of ecophysiological responses, adaptation processes and long-term consequences. Ann. For. Sci. 63: 625-644. doi: https://doi.org/10.1051/forest:2006042

Charrier G, Lacointe A, Améglio T (2018) Dynamic modeling of carbon metabolism during the dormant period accurately predicts the changes in frost hardiness in walnut trees Juglans regia L. Frontiers in Plant Science, 9: 1746. doi: https://doi.org/10.3389/fpls.2018.01746

Charrier G, Martin-Stpaul N, Damesin C, Delpierre N, Hänninen H, Torres-Ruiz J, Hendrik Davi H (2020) Interaction of drought and frost in tree ecophysiology: rethinking the timing of risks. HAL, 02475505, ver. 4 peer-reviewed and recommended by PCI Forest \& Wood Sciences. https://hal.archives-ouvertes.fr/hal$\underline{02475505 \mathrm{v} 4}$

Cheaib A, Badeau V, Boe J, Chuine I, Delire C, Dufrêne E, François C, Gritti ES, Legay M, Pagé C (2012) Climate change impacts on tree ranges: model intercomparison facilitates understanding and quantification of 


\section{₹3 $\mathrm{PCl}$

uncertainty. Ecology Letters 15(6): 533-544. doi: https://doi.org/10.1111/j.1461-0248.2012.01764.x Choat B, Jansen S, Brodribb TJ, Cochard H, Delzon S, et al. (2012) Global convergence in the vulnerability of forests to drought. Nature 491, 752-755. doi: https://doi.org/10.1038/nature11688

Choat B, Brodribb TJ, Brodersen CR, Duursma RA, López R, Medlyn BE (2018) Triggers of tree mortality under drought. Nature 558(7711): 531-539. doi: https://doi.org/10.1038/s41586-018-0240-X

Hacke UG, Stiller V, Sperry JS, Pittermann J, McCulloh KA (2001) Cavitation fatigue. Embolism and refilling cycles can weaken the cavitation resistance of xylem. Plant Physol., 125(2), 779-786.

doi: https://doi.org/10.1104/pp.125.2.779

Lloret F, Keeling EG, Sala A (2011) Components of tree resilience: effects of successive low-growth episodes in old ponderosa pine forests. Oikos, 120: 1909-1920. doi: https://doi.org/10.1111/j.1600-0706.2011.19372.x López de Heredia U, Venturas M, López R, Gil L (2010) High biogeographical and evolutionary value of Canary Island pine populations out of the elevational pinebelt: the case of a relict coastal population. J. Biogeogr. 37, 2371-2383. doi: https://doi.org/10.1111/j.1365-2699.2010.02367.x

Mackay DS, Roberts DE, Ewers BE, Sperry JS, McDowell NG, Pockman WT (2015) Interdependence of chronic hydraulic dysfunction and canopy processes can improve integrated models of tree response to drought, Water Resour. Res., 51, 6156-6176. doi: https://doi.org/10.1002/ 2015WR017244

Martin-StPaul N, Delzon S, Cochard H (2017) Plant resistance to drought depends on timely stomatal closure. Ecology Letters 20(11): 1437-1447. doi: https://doi.org/10.1111/ele.12851

Morin X, Augspurger C, Chuine I (2007) Process-based modeling of species' distributions: what limits temperate tree species' range boundaries? Ecology 88(9):2280-2291. doi: https://doi.org/10.1890/06-1591.1 PMID: 17918406.

Parmesan C (2006) Ecological and evolutionary responses to recent climate change. Annual Review of Ecology and Systematics 37, 637-669. doi: https://doi.org/10.1146/annurev.ecolsys.37.091305.110100 Rodriguez-Zaccaro FD, Valdovinos-Ayala J, Percolla MI, Venturas MD, Pratt RB, Jacobsen AL (2019) Wood structure and function change with maturity: Age of the vascular cambium is associated with xylem changes in current-year growth. Plant Cell Environ.42: 1816- 1831. doi: https://doi.org/10.1111/pce.13528 Sakai A, Larcher W (1987) Frost survival of plants. Ecol Stud. 62: 1- 321. doi: https://doi.org/10.1007/978-3$\underline{642-71745-1}$

\section{Revision round \#2}

2020-09-28

Dear authors,

I am really glad to inform you that your preprint has now been accepted with only minor editorial changes to improve the reading. Congratulations! It is definitely a very interesting manuscript for people working in plant abiotic stresses.

Regards

Rosana

Preprint DOI: https://hal.archives-ouvertes.fr/hal-02475505

\section{Reviewed by Sean Gleason, 2020-09-25 18:03}

Review of InteractionFrostDroughtPCIFWS_v3

General comments

I am overall very satisfied with the significant revisions to the manuscript. I have no major suggestions, but have offered many instances below where the wording could be corrected or clarified. All my suggestions are 
very minor, and I have offered alternative text in all cases, to make it easier for the authors. I think the document reads well and that the structure has been much improved. Also, please note that my editing suggestions have been made from the "InteractionFrostDroughtPCIFWSv2finalapp_changes.pdf" document, not the "...v3.pdf" doc (my line numbers won't patch the v3.pdf doc). I would like to thank the editors and handlers at $\mathrm{PCl}$ and the authors for giving me another opportunity to learn from their interesting research.

Kind regards,

Sean M. Gleason

Specific comments

Please note that these suggestions are from the "...changes.pdf" document, not the "...v3.pdf" document.

89: I would suggest using the transition "However" OR "On the other had", but not stringing both together.

$165:$ “...both constraints...” [plural]

176: “...pit membranes” [plural]. Though I might suggest "bordered pit membranes” or just "bordered pits" might be a bit more accurate.

177: Given the current disagreement among research groups on this issue (refilling) I might suggest, "However, it is likely..." or However, it is possible..." to acknowledge that this is still an open area of research.

178: Ditto - I would suggest "One possible refilling mechanism..."

179: “...involves osmoregulation via..." [delete "an”]

179: I would suggest "...generating low osmotic potential..."

181: I would suggest "A refilling mechanism has not yet been identified for conifers, but there is evidence that refilling likely occurs within several species..."

185: Lots of herbaceous plants generate root pressure as well. We've measured root pressure in maze in excess of $150 \mathrm{kPa} . .$. which would be sufficient to lift water $15 \mathrm{~m}$ high, in the absence of transpiration.

187: It's not clear why bubbles would "expand at lower tension" after freezing. The sentence that follows explains why gas would spread more widely (from conduit-to-conduit through damaged pit membranes), but not why an individual bubble within a conduit would "expand at lower tension". This would require a decrease in bubble surface tension (not a change in membrane characteristics). I might suggest a slight modification of the first sentence to bring it aligned with the second: "Embolism arising from the freezing of xylem sap and high tension arising from drought may interact such repeated freeze-thaw and drought events may lead to reduced embolism resistance (cite 10.1104/pp.106.085704 and 10.1007/s00425-003-0997-4). This is because the initial exposure to freezing temperatures may result in the deformation of the ultrastructure of bordered pit membranes, which are critical for preventing the spread of gas from one conduit into another (Christensen-Dalsgaard \& Tyree 2014)."

192: “...to cause plant death...”

194: “...without impairing their survival, which suggests...”

196: "High xylem embolism may be an empirical correlate with plant death, rather than a physiological cause..."

201: “...alternative hypotheses..." [plural]

208: “"Memory" (aka "priming") relates to a defensive plant response to either biotic or abiotic stress (Savvides et al., 2016), and is considered an active process that shifts or enhances the basal of resistance, but at the cost..."

212: "Memory requires... acclimation, which occurs prior to stress exposure." 
226: “...such an increase..."

253 “...vulnerability from frost-induced..."

278: “...promote aboveground dehydration..." [delete "the"]

300: “...plant transpiration, lower leaf water potential, and lower stomatal conductance." [lower T does not lead to lower psi_leaf and gs]

310 "...eliminate this potential benefit."

406 “...physiological drivers..." [plural]

410: “...climate..."

419: “...processes have been only studied..."

422: "Notably, do critical..."

447: “...function of the previous level of damage..."

450: delete "in interaction"

\section{Author's reply:}

Dear Rosana (+ Sean and Jordi),

Thank you for your comments and the help provided to help us improve this manuscrtipt. I am also very excited to be part of the PCI FWS adventure. On behalf of my co-authors, it is my pleasure to send you a revised version. We have taken all the comments into consideration. With respect to the controversies on embolism refilling, we have tried to differentiate between the repair of winter embolism, under pressure, for which the experimental facts are widely accepted and the repair of summer embolism, under tension, for which controversy exists. The present version now reads as (Page 8 of the formatted document): “Despite current controversies on the ability of plant to restore their hydraulic conductivity under tension (eg. Zwieniecki \& Holbrook, 2006; Brodersen et al., 2010; Lamarque et al., 2018), many tree species are able to restore their hydraulic conductivity under positive pressure, for instance to supply growth in spring (Hacke \& Sauter, 1996; Cochard et al., 2001). One refilling mechanism involves osmoregulation via solutes compounds generating low osmotic potential in the lumen of the vessels during winter (Ewers et al., 2001; Améglio et al., 2002), and eventually summer (Nardini et al., 2011). A refilling mechanism has not yet been identified for conifers, but there is evidence that refilling likely occurs within several species (Sperry \& Sullivan 1992; Sperry et al., 1994; Mayr et al., 2003; 2014)."

Thank you again for your help. I hope you will find this version recommendable by PCI Forest and Wood Science. Best regards,

Guillaume Charrier and co-auhors

\section{Revision round \#1}

\section{0-06-06}

Dear Dr Charrier and coauthors, Thank you for submitting your manuscript to PCI Forest and Wood Science, a new initiative to promote open science. Two referees have provided comments that you may find below this message. Both referees highlight that the topic is relevant, timely and of great importance to understand how climate constrains species natural distribution range. However, they found the manuscript difficult to follow in some parts and without a clear message and way forward suggesting to restructure the paper, specify the scale and time you are referring to in each section (Referee 1 ) and give more details about the modelling frame, construction and type (Referee 2). Some other issues were related to figures as they found 


\section{\{ 3 \} $P C l$

them sometimes a bit disconnected to the text and Referee 1 claims for more clarity, particularly in figure 1. Both agree in explicitly point out that your opinion on "the way forward" for scientist working in abiotic stresses, their interaction and species distribution will be of great value.

I hope the referees' comments and suggestions help you to improve the manuscript.

Regards Rosana

\section{Additional requirements of the managing board:}

As indicated in the 'How does it work?' section and in the code of conduct, please make sure that: -Data are available to readers, either in the text or through an open data repository such as Zenodo (free), Dryad or some other institutional repository. Data must be reusable, thus metadata or accompanying text must carefully describe the data.

-Details on quantitative analyses (e.g., data treatment and statistical scripts in R, bioinformatic pipeline scripts, etc.) and details concerning simulations (scripts, codes) are available to readers in the text, as appendices, or through an open data repository, such as Zenodo, Dryad or some other institutional repository. The scripts or codes must be carefully described so that they can be reused.

-Details on experimental procedures are available to readers in the text or as appendices.

-Authors have no financial conflict of interest relating to the article. The article must contain a "Conflict of interest disclosure" paragraph before the reference section containing this sentence: "The authors of this preprint declare that they have no financial conflict of interest with the content of this article." If appropriate, this disclosure may be completed by a sentence indicating that some of the authors are $\mathrm{PCl}$ recommenders: "XXX is one of the $\mathrm{PCI} X X X$ recommenders."

Preprint DOI: https://hal.archives-ouvertes.fr/hal-02475505

\section{Reviewed by Jordi Martínez Vilalta, 2020-05-23 21:03}

In this paper, Charrier et al. discuss the interaction between drought and frost impacts on tree ecophysiology, focusing on the relative timing of these two stress factors in relation to each other and to key phenological processes, and stressing their impact on the tree water and carbon economy. I concur with the authors that the study of the interactions between drought and frost in a temporal context is clearly underrepresented in the literature, and yet it is critical to understand plant responses to climatic constrains in the wild. The topic is thus timely and important. I have to say, however, that I had a hard time reading the text and found it difficult to follow several of the arguments and to understand the general flow of ideas. The paper as currently written is a combination of a review and an opinion piece, but in my view it lacks a clear message that would be effective at moving the field forward. The authors do not provide a common framework that unifies drought and frost impacts on a temporal context, nor give clear indication of what they think should be done in order to improve our understanding of this important interaction. Some of the figures seem a bit disconnected from the text and Figure 1 in particular does not convey a clear message (or I fail to grasp it; see specific suggestions below).

In my opinion the paper needs to be restructured to provide a clearer and more coherent contribution. In many instances the authors mix different temporal, spatial and organizational scales without properly acknowledging the different factors at play. To give just an example, in the paragraph starting in L325 the authors start discussing freeze/thaw-induced embolism and frost cracks, end up by discussing stand-level effects on competition for water (L331-332) and start the next paragraph referring to changes in the density and porosity of the pit membrane (L333-...). I find it essential to clarify the scale of the mechanisms being discussed from the beginning of the paper (perhaps narrowing the focus to within-year seasonal patterns) and then organize the text in a logical way so that the reader knows what to expect in each section. It seems to me that it would be much more effective to consider several scenarios regarding the order and seasonal timing of drought and frost and discuss the key knowns and unknowns in each case. Somehow the paper now fails to provide a clear agenda to advance the study of drought - frost interactions. 
The text also needs a careful revision by the authors to improve English usage and the clarity of several sentences. I provide specific suggestions below, but they are not exhaustive.

More detailed or technical comments: Title: you mean '...rethinking the timing of risk'?

L17: 'areas'

L25, 26, 30, ...: I think that something like 'stress factors' would be more appropriate than 'constraints' here and elsewhere in the ms.

L34-35: I do not understand this sentence.

L48: I would tone down a bit the text, for example 'abiotic factors are typically more relevant...'

L53-55: that seems to be very a temperate-centered view, which is fine, but the biome or ecosystem type you are referring to should be clear from the beginning.

L79: 'composition' better than 'biodiversity'?

L85: and ecologists?

L91: I would limit the use of Latin phrases, as they tend to make the text unnecessarily obscure.

L101: delete 'can'.

L101-104: this is not exact. See, for instance: Miao et al. 2009 (American Naturalist 173: 113-118), Anderegg et al. 2013 (Tree Physiology 33: 701-712), Batllori et al. 2017 (Ecosphere 8: e01906), Hossain et al. 2018 (Tree Physiology 39: 6-18).

L114: 'chaotic behavior' has a very specific mathematical definition, so I suggest using a more general term here (e.g., 'complex behavior').

L121-122: simplify text (e.g., 'to promote an integrative perspective...').

L123: replace 'damages' by 'stress factors'?

L126: 'How do...'

Frames \#1 and \#2: it seems to me that these boxes should be synthesized substantially and simply provide a short summary of our current understanding of drought and frost stress, if possible in a single paragraph for each stress factor. In the case of drought the framework seems to be almost entirely based on McDowell et al. (2008), which was obviously an extremely influential paper but that in my opinion no longer reflects the consensus view on drought-induced mortality. When a water balance approach and consideration of tissue dehydration is advocated for, a reference to Martínez-Vilalta et al. 2019 (New Phytologist 223: 22-32) would seem appropriate. In Frame \#2 (2nd paragraph) you seem to imply that water in plant tissues freezes as temperatures go below $0 \stackrel{\circ}{ }{ }^{\circ}$, which is not the case (substantially lower temperatures are required in many cases).

Frame \#3: similarly, I think the arguments here could be greatly synthesized (e.g., the text in L148-153 could be deleted). In addition, I would consider moving the key ideas developed in this box to the main text of the ms. instead of presenting them in a box.

L202: what does 'structural vs annual' mean?

L207-208: the theory underlying the relationship between water content and water potential in plant tissues have been developed extensively for at least 50 years; why refer to an equation developed for soils?

L250: 'approximation' instead of 'approach'?

L251: 'make'.

L253-255: but this seems to contradict the previous sentence. 
L256: you mean 'concepts' instead of 'hypotheses'? In any case, it is important to clarify the terminology you introduce. For instance, what is the difference between 'memory' as you define it and 'acclimation', a much more widely used concept in plant ecophysiology?

L279-280: you mention that on passing, but this is quite critical, right? (Autumns tend to be very wet in many if not most temperate systems).

L290, 297: it is totally unclear to me what this 'drought stress intensity' is exactly.

L304: please explain all abbreviations ('FT').

L316: but this section deals with the opposite effect, right? Please clarify the text.

L329: why 'should result'?

L333-348: this whole paragraph is confusing to me.

L387-388: 'diurnal dynamics' of what?

L395. 'Keenan'.

L398: delete 'thus'?

L411: 'events'.

L412-415: but reduced leaf area should be advantageous under drought, right?

L436: 'interaction' instead of 'crossing effects'?

L449: delete 'as mentioned' and refer to '(Frame 3)'.

Figure 1: there are several aspects of this figure I don't fully understand. For instance, why is 'frost hardiness' between 'summer' and 'winter'? why is starch associated to 'summer' and solutes to 'winter'? What does a positive effect of 'Budburst' on water stress mean? Are you referring to the timing of budburst? Please be more clear and specific. In addition, using solid and dashed lines for positive and negative relationships would make the diagram clearer, I think.

Figure 3: a more explicative caption and a clearer connection with the main text is required here, I believe.

Figure 4: a 'Late drought' in February?

\section{Reviewed by Sean Gleason, 2020-06-05 00:59}

\section{General comments}

The authors offer a theory and framework for developing process-based models with the aim to provide better prediction of species distribution limits in the face of climate change. This is certainly an important topic and I found their approach intuitive and well-thought-out. The figures were also helpful in explaining their ideas and I enjoyed reading the manuscript. Although it could be argued that much of what is presented is not especially novel in itself (e.g., modeling interactions, drought tolerance vs frost tolerance, etc), I don't think this detracts from the manuscript. For example, the fact that there has yet been no successful attempt to model these kinds of interactions (hydraulics, carbon, phenology) to predict the outcome of climate change, does indeed suggest that the manuscript and topic are timely.

One suggestion I have would be to explain a little better how the empirical relationships they so welldescribe could be used (or are being used) to build models representing underlying processes and their interactions. For example, the end of the introduction states, "This framework would be crucial to understand local mortality dynamics and ultimately to improve actual species distribution models". I agree strongly with this. And although they discuss the theory and conceptual steps needed to develop such a 


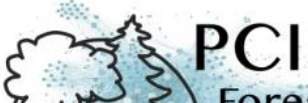

model (and identify important obstacles) (Frame 3), it's not clear to me exactly how this would happen... and I think the authors' thoughts on this would be very helpful to others. Do the authors see this a being a grassroots effort to build a model from scratch, which has all the ingredients (e.g., processes, functions, submodels, etc) needed to examine these interactions, or do they see this more like a patchwork effort that would take models or parts of them (the actual code) and integrate these together into one massive model such that all interactions can be assessed? Would this be a land-surface model or an ESM then? If so, should we start with something like CLM5 and modify it such that it has all the bits and pieces needed to assess these important interactions (this seems contrary to Frame \#3)? Or do we start somewhere else entirely? I guess I'm looking for a paragraph that lays out the way (or ways) forward. Are there models and labs out there that could start working together on this issue (maybe they already are?). Would this require additional funding, or additional leadership? Where could these resources potentially come from? I'm not looking for much - just a paragraph or two about how all this could potentially happen (or is already happening). On the other hand, maybe this is beyond the scope of what the authors want to accomplish with this manuscript.

On lines 447-449 the authors suggest it is a "prerequisite" that we first improve our understanding of these interactions (presumably via field experiments/observations). Do they really mean this, i.e, that model development should wait until we can improve our understanding of the biology. It seems to me that a properly parameterized model with even a few of the discussed process would help inform our understanding the biology itself, or at least re-direct our experimental efforts.

\section{Specific comments}

16: Really? Do we know this? For example, considering the second sentence ("heat waves and drought") have the competitive interactions between species been experimentally eliminated from the effects of heat and drought in these studies? ...seems like this should still be a very open area of research (environment vs competition). That said, I agree with the authors that models examining the interactions discussed here should not (at least initially) consider competition.

34: I might suggest, “...exposure to a constraint".

42: Rather than "the tree", I might suggest something more general (e.g., "plants", "species", etc).

45-47: The authors should be allowed their interpretation of the literature. However, for me, it's a very bold statement to suggest that abiotic factors are in fact the main drivers of distribution limits and evolution. I'm not saying that I think they are definitely wrong (in fact, I'm incline to at least partially agree), but I don't think the evidence is very strong for their claim. For example, the cited Klanderud et al paper suggests that there is a shift in the relative importance of abioitc and biotic drivers across the temperature gradient, and also emphasized interaction between biotic and abiotic factors. I would also question the efficacy of correlative analysis to address this question altogether. Just to make my point, I can very easily find two papers (the number cited by the authors) in support of the opposite claim, i.e., that competitive exclusion is the main factor defining distribution boundaries (e.g., doi.org/10.1111/jbi.12907). Perhaps it would be more fair to point out that this is still an open question, and an important one. I'm also not sure it's really necessary to eliminate competition as a important factor at the edges of distributions. I think the authors' aims with this work and their analyses are just as valid and important.

Box 1: “...depends to a large extent..."

Box 1: It's not clear what is meant by "hydric insulation".

Frame 2: Delete extra ")" after “...Koerner 2015)."

Frame 3(ii): By "based on experimental data" do the authors mean that this initial model should be wholly empirical, or should it be mechanistic but validated using experimental data? Or, is this a recipe for building models more generally (process-based and empirical)? I'm just trying to understand the gory details of how the linkages between responses and inputs (or independent variables) work.

205: "McDowell" 
207: I would think that the main difficulty would not be water-release relationships so much (i.e., psi soilwatercontent), but rather, the unsaturated soil water conductance (i.e., solution of the Richards equation), and thus, water flux within the soil and between the soil and root (xylem).

310: I might suggest a very short definition of what is meant by "fatigue", at least the explanation provided in the cited reference. Maybe something like, "...fatigue, i.e., physical or chemical deformation of the pit ultrastructure."

327: It is not clear what is meant by "punctuations of the vessels [conduits]". Do the authors mean that the frost crack is bringing air in closer proximity to conduits under tension, and therefore, facilitating air entry? If so, I don't think this would result in the spread of gas from "conduit to conduit" (i.e., air-seeding through the bordered pit connections).

368-369: Damn... I never considered this.

Figure 3. I might suggest replacing the Christian symbol here with something secular to represent cell death... skull and bones, perhaps? A picture of a McDonalds restaurant? Or perhaps just the words "death", to be clear?

I would like to thank the authors and editor for giving me the opportunity to review this interesting review. I sincerely hope that at least a few of my comments will be helpful towards revising their manuscript.

Kind regards,

Sean M. Gleason

\section{Author's reply:}

